Document downloaded from:

http://hdl.handle.net/10251/74910

This paper must be cited as:

Ferri, J.; Noe, E.; Llorens Rodríguez, R. (2015). The Spanish version of the coma recovery scale-revised: Events on a correct timeline. Brain Injury. 29(7-8):1002-1003. doi:10.3109/02699052.2015.1022884.

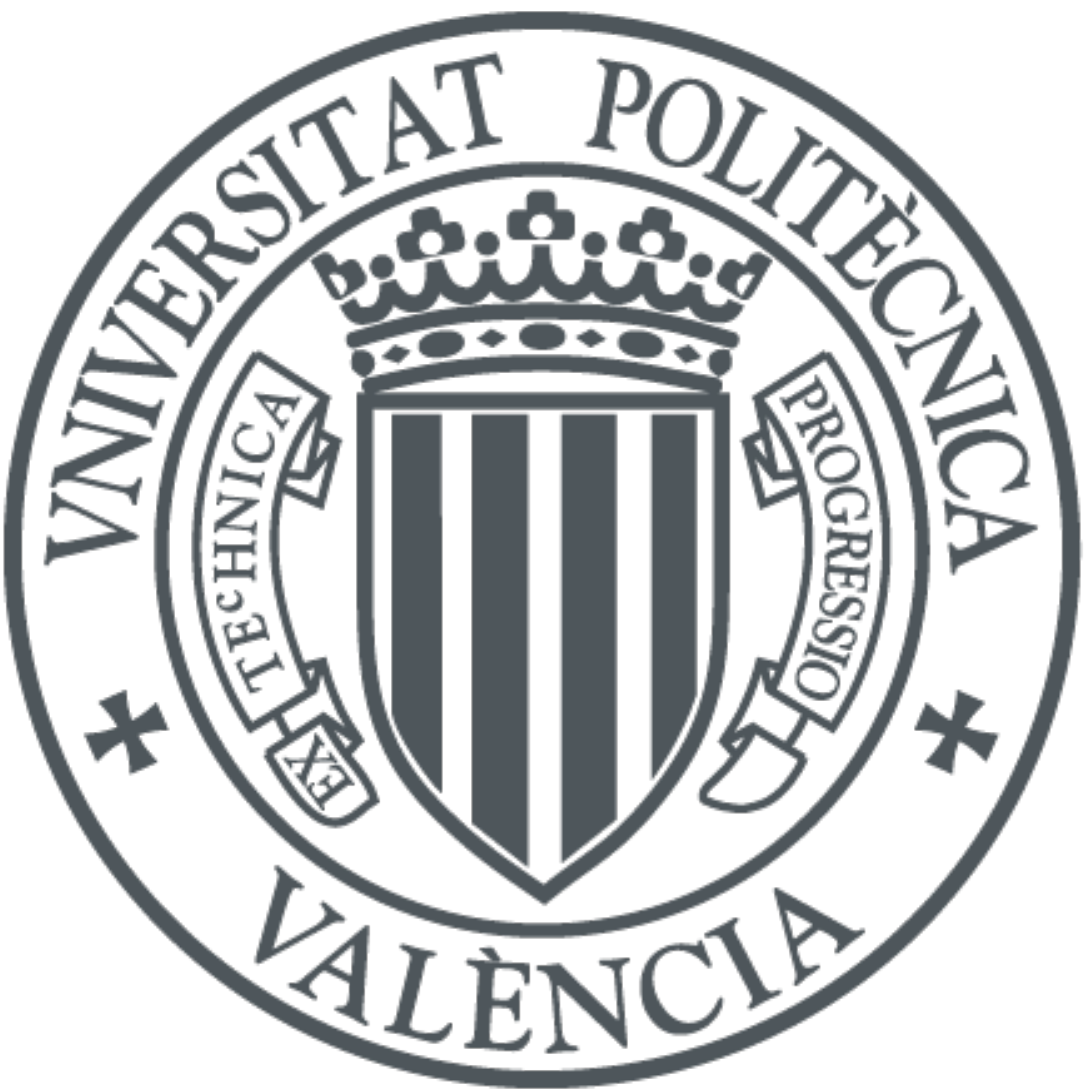

The final publication is available at

http://dx.doi.org/10.3109/02699052.2015.1022884

Copyright Taylor \& Francis

Additional Information 


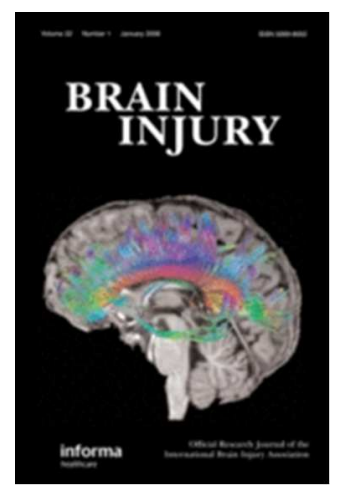

\section{The Spanish version of the Coma Recovery Scale-Revised: Events on a correct timeline}

\begin{tabular}{|r|l|}
\hline Journal: & Brain Injury \\
\hline Manuscript ID: & Draft \\
\hline Manuscript Type: & Letter to the Editor \\
\hline Keywords: & $\begin{array}{l}\text { Glasgow Coma Scale, minimally conscious state, vegetative state, } \\
\text { assessment }\end{array}$ \\
\hline \multicolumn{2}{|l}{} \\
\hline
\end{tabular}

SCHOLARONE ${ }^{m}$

Manuscripts 


\section{Letter to the editor}

The assessment of the degree of consciousness has traditionally posed a challenge for clinicians. Different structured scales have been presented to quantify the severity of the disorder of consciousness. The Glasgow Coma Scale (GCS), the Disability Rating Scale (DRS), the Coma Recovery Scale, later revised (CRS-R), and the Loewenstein Communication Scale (LCS) ${ }^{1}$ are good examples. However, the interpretation of the patients' reactions has been reported to be dependent on the variability of their behavior and arousal level, but also on the examiner ${ }^{2}$. This sensitivity urges to minimize the factors that can lead to misinterpretation of the signals. In this regard, the use of assessment tools in native language may help clinicians to avoid mistakes derived from particularities of each language. In a recent paper, Tamashiro and colleagues have presented a validation of a Spanish version of the CRS- $\mathrm{R}^{3}$. The concurrent validity of the translated scale with the GCS and the DRS, and its inter-rater reliability are presented. However, the authors stated that no Spanish version was available at the moment of publication, which is not true. A Spanish version of the CRS-R was published two years before by our group ${ }^{4}$, in a prospective study with a cohort of patients who presented disorders of consciousness after severe brain injury. The scale was also used for assessing patients in vegetative state and minimally conscious state in a randomized placebo-controlled trial to determine the effectiveness of a single daily dose of Zolpidem ${ }^{5}$. To create our version, the CRS-R was back-translated to Spanish and refined by four clinicians, who finally agreed on the definitive version. This version was, in fact, provided as a supplementary appendix to the article, and is available for examination. A similar method has been used by our colleagues to create their version. We regret that a simple search in a scientific library engine (as PubMed.gov) before the elaboration of the second Spanish version of the CRS-R including the keywords 'coma 
recovery scale revised Spanish' would have displayed our paper, thus avoiding duplication of efforts. The variability of the patients' behavior, the difficulties in detecting subtle changes, and to unambiguously interpret them could be better coped with more collaboration between groups. In this case, it could have led to a greater sample, which could have helped both groups to extract more reliable conclusions.

As a proof, we assessed the concurrent validity of the CRS-R, the GCS, the DRS, and the LCS using the data derived from the initial assessment of our study. Interestingly, participants were very similar in both studies (Table 1).

Insert table 1 about here

While all the participants in our study ( $\mathrm{n}=32$ ) were assessed with the CRS-R, the DRS, and the LCS, only participants with traumatic brain injury $(n=15)$ were assessed with the GCS. Replicating the procedures of the study by Tamashiro et al. we estimated the Spearman correlations of the scores of the three scales collected from the participants in our study. Surprisingly, the correlation coefficient between our version of the CRS-R and the DRS $(\mathrm{r}=-0.53, \mathrm{p}<0.01)$ was almost equal to their finding $(\mathrm{r}=-0.54, \mathrm{p}<0.01)$. This tendency was also supported by the correlation with the LCS $(r=0.71, p<0.01)$. However, we did not find significant correlation with the GCS. The limited sample of participants assessed with this scale, and the lower sensitivity of the GCS to small changes could have led to this result ${ }^{1}$. This was evidenced by the fact that 12 participants $(80 \%)$ had a score of three in this scale in the baseline.

In conclusion, we commend the authors for their work at validating their version of the scale, but we encourage them to better research previous work. This could have 
avoided not only the replication of work, which seems to be evidenced by the similar characteristics of both versions, but also the dilemma for Spanish-speaking clinicians of choosing one version or another. 


\section{Bibliography}

1. American Congress of Rehabilitation Medicine BI-ISIGDoCTF, Seel RT, Sherer M, Whyte J, Katz DI, Giacino JT, Rosenbaum AM, Hammond FM, Kalmar K, Pape TL and others. Assessment scales for disorders of consciousness: evidence-based recommendations for clinical practice and research. Arch Phys Med Rehabil 2010;91(12):1795-813.

2. Schnakers C, Vanhaudenhuyse A, Giacino J, Ventura M, Boly M, Majerus S, Moonen G, Laureys S. Diagnostic accuracy of the vegetative and minimally conscious state: clinical consensus versus standardized neurobehavioral assessment. BMC Neurol 2009;9:35.

3. Tamashiro M, Rivas ME, Ron M, Salierno F, Dalera M, Olmos L. A Spanish validation of the Coma Recovery Scale-Revised (CRS-R). Brain Inj 2014;28(13-14):1744-7.

4. Noe E, Olaya J, Navarro MD, Noguera P, Colomer C, Garcia-Panach J, Rivero S, Moliner B, Ferri J. Behavioral recovery in disorders of consciousness: a prospective study with the Spanish version of the Coma Recovery Scale-Revised. Arch Phys Med Rehabil 2012;93(3):428-33 e12.

5. O’Valle M, Moliner B, Navarro MD, Balmaseda R, Colomer C, Ferri J, Noé E. Accepted Abstracts from the International Brain Injury Association's Ninth World Congress on Brain Injury. Brain Injury 2012;26(4-5):519. 
Table 1. Comparison of the participants in both studies

\begin{tabular}{|l|c|c|}
\hline & $\begin{array}{c}\text { Participants of the study } \\
\text { by Noé et al. }\end{array}$ & $\begin{array}{c}\text { Participants of the study } \\
\text { by Tamashiro et al. }\end{array}$ \\
\hline Age (years) & $40.2(16-64)$ & $30.0(18-62)$ \\
\hline Chronicity (days) & $118(38-370)$ & $146(28-1154)$ \\
\hline Gender (n, \%) & $22(68.8 \%)$ & $23(65.7 \%)$ \\
Males & $10(31.3 \%)$ & $12(34.3 \%)$ \\
Females & $15(46.9 \%)$ & $24(68.6 \%)$ \\
\hline Etiology (n, \%) & $12(37.5 \%)$ & $4(11.4 \%)$ \\
Traumatic brain injury & $5(15.6 \%)$ & $6(17.1 \%)$ \\
Stroke & $0(0 \%)$ & $1(2.9 \%)$ \\
Anoxia & $8.47 \pm 7.74$ & $9.31 \pm 4.39$ \\
Tumor & $23.59 \pm 2.45$ & $23.20 \pm 1.89$ \\
\hline CRS-R & & \\
\hline DRS & & \\
\hline
\end{tabular}

URL: http://mc.manuscriptcentral.com/tbin 